\title{
Infrasound associated with the deep $M 7.3$ northeastern China earthquake of June 28, 2002
}

\author{
Il-Young Che ${ }^{1}$, Geunyoung Kim ${ }^{1}$, and Alexis Le Pichon ${ }^{2}$ \\ ${ }^{1}$ Earthquake Research Center, Korea Institute of Geoscience and Mineral Resources, Daejeon, Korea \\ ${ }^{2}$ CEA, DAM, DIF F-91270 Arpajon, France
}

(Received April 11, 2012; Revised July 13, 2012; Accepted July 23, 2012; Online published March 6, 2013)

\begin{abstract}
On 28 June, 2002, a deep-focus $(566 \mathrm{~km})$ earthquake with a moment magnitude of 7.3 occurred in the ChinaRussia-North Korea border region. Despite its deep focus, the earthquake produced an infrasound signal that was observed by the remote infrasound array (CHNAR), $682 \mathrm{~km}$ from the epicenter, in South Korea. Coherent infrasound signals were detected sequentially at the receiver, with different arrival times and azimuths indicating that the signals were generated both near the epicenter and elsewhere. On the basis of the azimuth, arrival time measurements, and atmospheric ray simulation results, the source area of the infrasonic signals that arrived earlier were located along the eastern coastal areas of North Korea and Russia, whereas later signals were sourced throughout Japan. The geographically-constrained, and discrete, distribution of the sources identified is explained by infrasound propagation effects caused by a westward zonal wind that was active when the event occurred. The amplitude of the deep quake's signal was equivalent to that of a shallow earthquake with a magnitude of approximately 5. This study expands the breadth of seismically-associated infrasound to include deep earthquakes, and also supports the possibility that infrasound measurements could help determine the depth of earthquakes.
\end{abstract}

Key words: Infrasound, deep earthquake.

\section{Introduction}

Studies of earthquake-generated infrasound have benefitted from recent worldwide deployment of modern infrasound arrays; an example of which is the global infrasound network of the International Monitoring System of the Comprehensive Nuclear Test-Ban Treaty (Christie and Campus, 2010). These studies have described the characteristics of infrasound signals from large earthquakes and have analyzed the infrasound signals to reconstruct earthquake source regions and interpret coupling phenomena between ground motion and the atmosphere (Le Pichon et al., 2002, 2006). Special emphasis has been placed on solving the problem of coupling between atmospheric, and ground, motions caused by earthquakes in order to properly interpret the signatures of earthquake-generated infrasound. Although the use of infrasound data to interpret an earthquake's source mechanism is not comparable to interpretations based on seismological data, seismic and infrasonic wave fields can be combined to characterize the natural phenomena associated with earthquakes. The detection limits of infrasound technology have been expanded beyond atmospheric phenomena to include phenomena in the Earth's interior.

Infrasound signals associated with the ground motion produced by a large earthquake are usually classified ac-

Copyright (C) The Society of Geomagnetism and Earth, Planetary and Space Sciences (SGEPSS); The Seismological Society of Japan; The Volcanological Society of Japan; The Geodetic Society of Japan; The Japanese Society for Planetary Sciences; TERRAPUB.

doi:10.5047/eps.2012.07.010 cording to the source location relative to the epicenter and receiver locations as local, epicentral, or secondarysource infrasound. Disturbing the air pressure around an infrasound source requires significant ground motion (e.g., large-amplitude surface waves). Most studies have focused on phenomena associated with shallow earthquakes that take place in the Earth's crust. The 1994 Bolivia $M_{\mathrm{w}} 8.3$ earthquake, which was in the mantle at a depth of $647 \mathrm{~km}$ (Frohlich, 2006), generated strong ground motion, which, in turn, could have generated infrasound. Infrasound from a deep-focus earthquake, however, has not yet been documented.

On 28 June, 2002, a deep-focus earthquake occurred near the China-Russia-North Korea border at a depth of $566 \mathrm{~km}$, with a moment magnitude of $M_{\mathrm{w}} 7.3$, in association with reverse fault displacement along a northeaststriking structure (Park and Mori, 2008). This deepfocus earthquake occurred near the base of the WadatiBenioff zone, where the Pacific oceanic plate begins its decent into the mantle $(43.803 \mathrm{~N}, 130.655 \mathrm{E}, 17: 19: 30 \mathrm{UTC}$, http://earthquake.usgs.gov). Despite its deep focus, infrasound signals associated with this earthquake were documented at a remote seismo-acoustic array, CHNAR, in South Korea. This study reports infrasound data from this earthquake, and is the first report of infrasound signals associated with a seismic event in the upper mantle. The characteristics of the infrasound received by the array were investigated, and source locations were estimated using an inverse location procedure, and both infrasonic and seismic wave parameters. To explain the geographically-limited source 

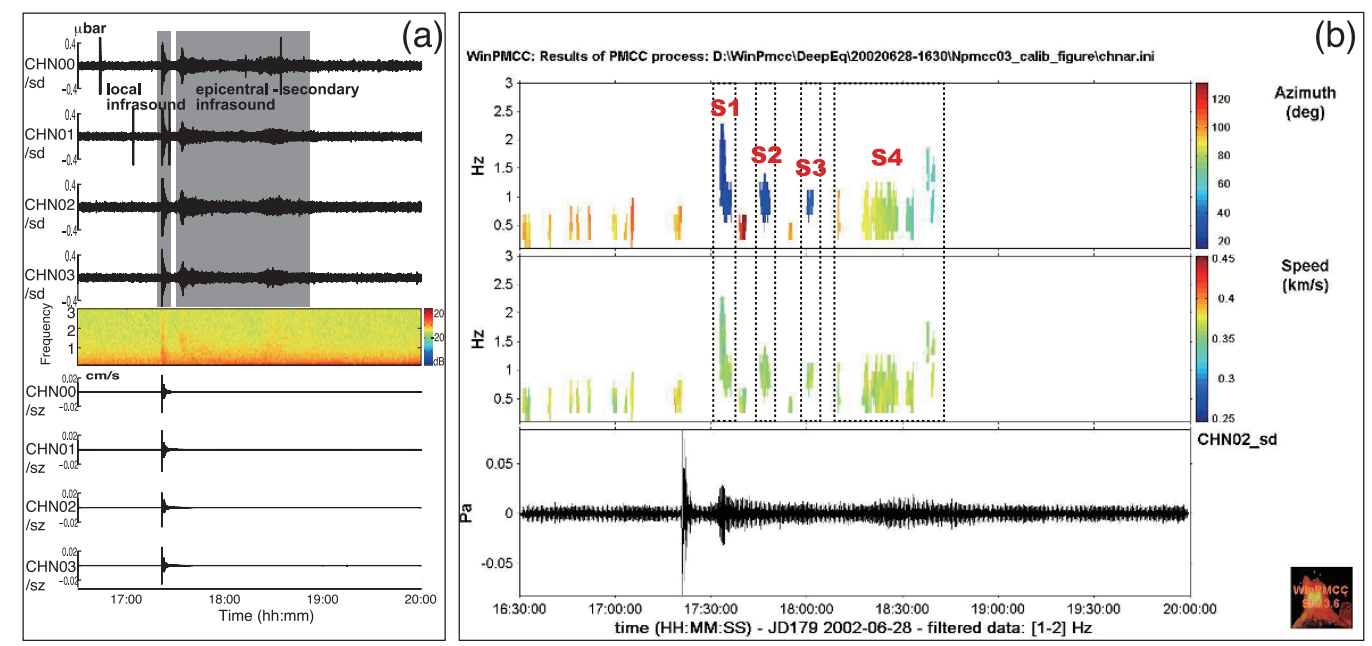

Fig. 1. (a) Acoustic (upper) and seismic (lower) waveforms recorded at CHNAR. A spectrogram of acoustic data (CHN03) is plotted under the waveform. Gray boxes indicate dominant infrasound arrivals, and local and epicentral secondary-source infrasound. (b) Results of progressive multi-channel correlation calculations on the infrasonic recordings in terms of azimuth and apparent velocities in the frequency range of $0.1-3.0 \mathrm{~Hz}$. Sequential and discrete detection results are marked by boxes labeled S1-S4, respectively.

area for the infrasound, ray tracing in an atmospheric model was undertaken and compared with the observed data. Infrasound amplitude and duration were compared with infrasound records from relatively shallow, large earthquakes reported in previous studies.

\section{Infrasound Signal Detection}

The Korea Institute of Geoscience and Mineral Resources (KIGAM), in collaboration with the Southern Methodist University, operates an infrasound network in South Korea that consists of eight seismo-acoustic arrays. Development of the arrays began in 1999 with the goal of detecting distant infrasound signals from natural and anthropogenic phenomena in and around the Korean Peninsula. However, when the deep-focus earthquake occurred in June 2002, only one seismo-acoustic array of the network (CHNAR) was functioning. CHNAR, a triangular four-element 1-km-aperture seismo-acoustic array, was equipped with GS-13 short-period seismometers and colocating modified Validyne DP250 microbarometers that have a pass-band of $0.05-20 \mathrm{~Hz}$, connected to 11 radial arms consisting of 8 -m-long porous hoses at the surface to reduce infrasound background noise around the sensors (Stump et al., 2004). The distance from the array to the epicenter of the earthquake was $682 \mathrm{~km}$, and the distance to the hypocenter was $886 \mathrm{~km}$. The true azimuth from the array to the epicenter was $24.6^{\circ}$ (Fig. 2).

Figure 1(a) shows the seismic and infrasound signals from the deep-focus earthquake that were recorded at CHNAR. Infrasound channels are band-pass filtered for a frequency range of 1-2 Hz. Local infrasound signals that were aligned to, and coeval with, the dominant seismic $P$ wave of the event were induced by coupling of ground motion passing beneath the microbarometers. The initial signal was followed by long-duration infrasound signals lasting about 90 minutes after the seismic event; such long wave trains were presumably generated by ground motion around the epicenter and in other regions.

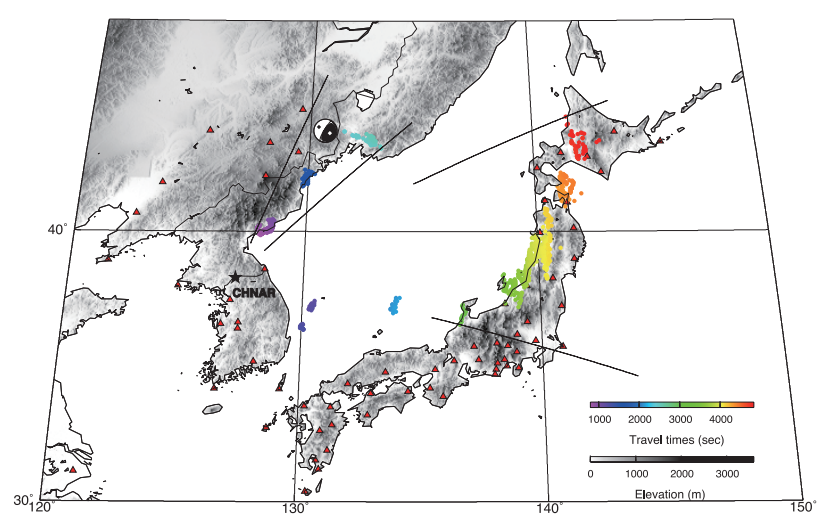

Fig. 2. Infrasound source location results based on a grid search using the observed infrasound wave parameters and the infrasound source map. Colored dots indicate infrasound source locations, colored according to travel time. The star marks the location of the seismo-acoustic array CHNAR and triangles indicate seismological stations used for measuring real peak ground motions for the location procedure.

A progressive multi-channel correlation method (PMCC, Cansi, 1995) was applied to detect coherent infrasound signals and to estimate the wave parameters of the signals, such as the back azimuth and apparent velocity. In this study, we used the PMCC method to make regional wavefield estimates focusing on a group velocity range of $0.25-0.40 \mathrm{~km} / \mathrm{s}$ using a window length of $60 \mathrm{~s}$ and a frequency band of $0.1-$ $3 \mathrm{~Hz}$. Figure 1(b) displays the estimates of azimuth and apparent velocity of the coherent signals detected by the array. The correlation method was applied to the pre-seismic $P$ arrival to identify prevailing background infrasound noise (microbaroms). Microbaroms with a frequency below $1 \mathrm{~Hz}$ arrived at the array from the east $\left(95.9 \pm 5.3^{\circ}\right.$; Fig. 1(b)). Some signals, marked by dotted boxes in Fig. 1(b), included several discrete infrasound signal groups that were detected by the progressive multi-channel correlation. On the basis of the azimuth values, the first three signal groups (S1-3) arrived at CHNAR from the northeast (mean azimuths are 
$25.1^{\circ}, 27.8^{\circ}$ and $35.4^{\circ}$, respectively), whereas a later signal (S4) of longer duration arrived from southeastern $\left(100.3^{\circ}\right)$ to northeastern $\left(55.8^{\circ}\right)$ directions.

\section{Infrasound Source Location}

The location of an earthquake-related infrasound source can be calculated using an inverse location procedure and the earthquake's seismic and infrasound data (Le Pichon et al., 2002). The location of each detected infrasonic signal can be back-projected on its back-azimuth value to the source location. The distance of the projection is inversely determined by fitting the observed infrasound arrival time to the calculated time, which includes seismic propagation time from the hypocenter to any source point and infrasound travel time from the source point to the receiver. This study used a method that is similar to the inverse location method and incorporates ray-tracing results to calculate azimuth deviation and celerity variation depending on sourceto-receiver paths (ray-tracing is discussed further below). Celerity refers to a propagation velocity that is calculated by dividing the propagation range from the source to the receiver by the travel time. From the ray-tracing, the celerity and azimuth deviation of eigenrays were calculated for each geographical location to the receiver, covering a broad source area within $34-44^{\circ} \mathrm{N}$ and $125-145^{\circ} \mathrm{E}$ to include all possible sources. The resulting maps show how these parameters vary depending on the location of the assumed sources. In addition to the maps, times of peak ground motion at sources were interpolated from real seismological data. An infrasound source map was then made, in which each geographic point has its own possible infrasound travel time that includes both the propagation time of realistic seismic waves and infrasound calculated from the celerity map. Each point on the map has a corrected azimuth value that is calculated from the azimuth deviation map. For azimuths, this approach allows correction of azimuth deviation along a great circle, where differences are caused by different propagation paths and infrasound phases. Finally, the best source locations for each detected signal (points in Fig. 1(b)) were grid-searched from the infrasound source map in terms of infrasound arrival time and azimuth measured at the receiver.

Results of the grid search location procedure for the epicentral-secondary infrasound signals (Fig. 2) show that all source locations were east of the receiver. Three detection groups (S1-3) were located along the eastern coastal area of North Korea and Russia. Later arrivals (S4) were located in a broad area in the central to northern part of the Japanese islands. Other detection groups with low frequency, between detection groups S1-S3, were located in ocean areas. These detections have azimuth and frequency $(<1 \mathrm{~Hz})$ characteristics that are similar to background coherent noise and were interpreted to be related to microbarom activity at the time of the earthquake but to be unrelated to its ground motion. Group S4 was identified as signals generated by ground motions because of $(i)$ its frequency content (up to $1.8 \mathrm{~Hz}$ ) and amplitude which are relatively higher/larger than those of microbaroms, and, mainly, (ii) due to a large azimuthal variation (from 100.3 to $55.8^{\circ}$ ) characterizing earthquake-associated infrasound produced

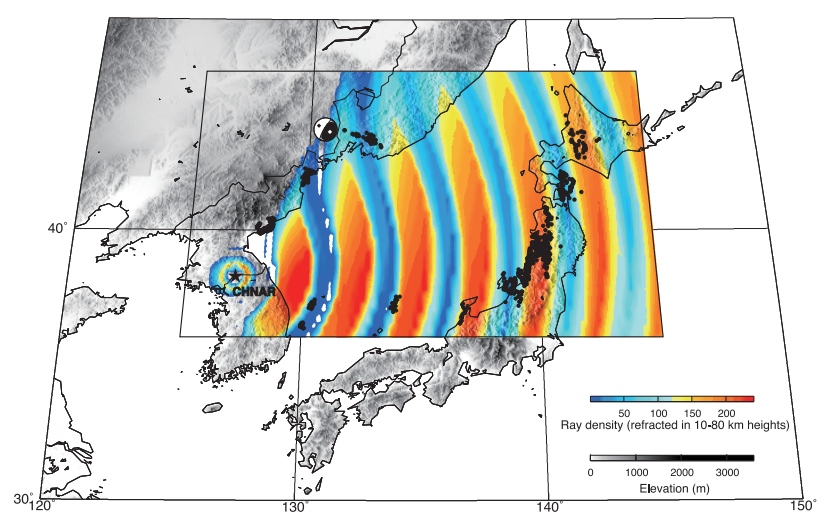

Fig. 3. Ray density map for a large potential source area. The color code indicates a number of eigenrays passing through the receiver (CHNAR). Uncolored areas in the rectangle are areas from which no ray was predicted to be detected at CHNAR. Black dots are infrasound source location results from Fig. 2.
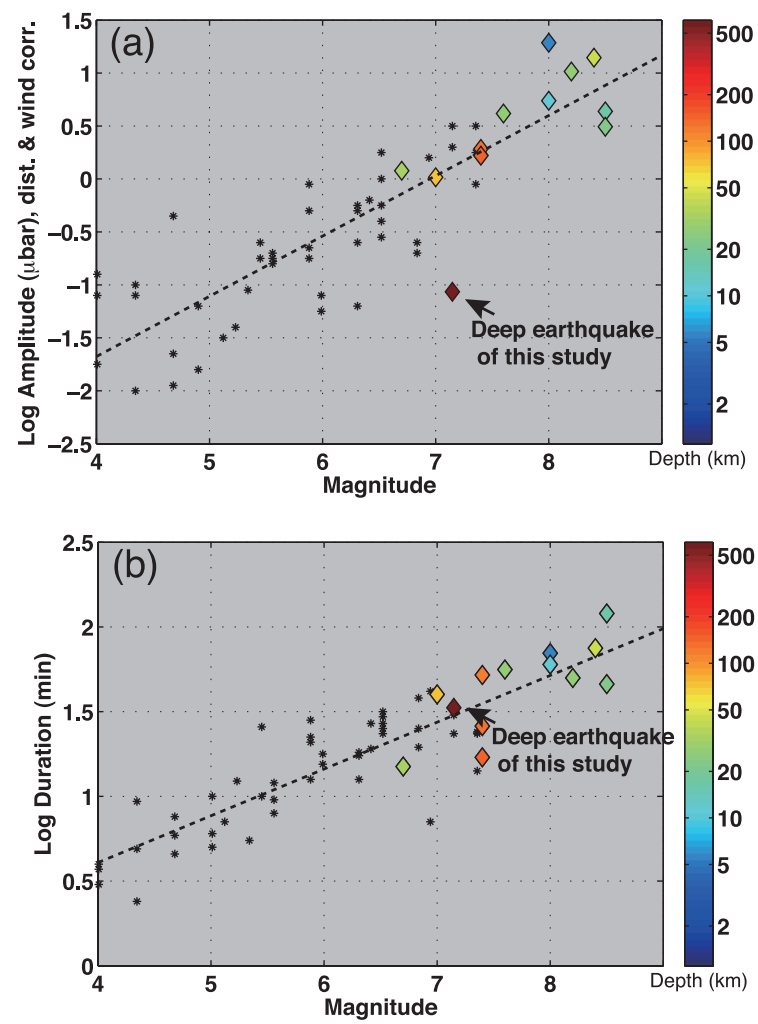

Fig. 4. Relation of earthquake magnitude with (a) corrected amplitude and (b) signal duration of infrasound signals comparing amplitude and duration of signals from deep earthquakes to shallow earthquakes (stars indicate observations from Mutschlecner and Whitaker, 2005; diamonds indicate events analyzed by Le Pichon et al., 2006 and the studied earthquake).

along the Japanese island arc (Che et al., 2007).

In general, topographically-elevated areas are good infrasound radiators when an earthquake's seismic waves pass through these areas and vertical ground motion interacts with air masses above them. The location results in Fig. 2 indicate geographically-limited coastal areas, rather than regions at higher elevation close to the epicenter. If the topographically-elevated areas had been major radiators of the earthquake, CHNAR should have recorded abundant 
signals excited from the mountainous areas, rather than the coastal areas and Japanese islands indicated by the results. The location results for the dominant infrasound signals, particularly S1, S2, and S3, are located at nearly equal spacings of approximately $230 \mathrm{~km}$.

\section{Infrasound Ray-tracing}

To explain the asymmetry of the location results and to make an infrasound source map, atmospheric ray-tracing was performed for a broad source area using empirical atmospheric models (Horizontal Wind Model/Mass Spectrometer, Incoherent Scatter: HWM93/MSISE-90 (Hedin, 1991)). Ground motions in a widespread area that includes the epicentral region were potential infrasound sources, and thus a large possible source area (box in Fig. 3) was defined for the ray-tracing. Grid points at $0.2^{\circ}$ spacing were set as point sources and a set of rays with different take-off angles were shot to CHNAR from each grid point. Rays intersecting a disk of radius $20 \mathrm{~km}$ centered on CHNAR were selected to construct an eigenray density map (Antier et al., 2007).

Figure 3 shows the eigenray density map for the entire potential source area. Within the wide source area (box), color codes indicate populations of eigenrays for each grid source; uncolored areas in the box indicate the absence of infrasound arrival due to atmospheric propagation effects. At the time of the earthquake, strong westward zonal winds would have limited detection to those sources east of CHNAR. A large population of eigenrays (warm colors) is repeated in concentric bands, with a spacing of approximately $220 \mathrm{~km}$, and resulted from multiple reflections of the dominant stratospheric phase(s) onto the ground. Although the grid-searched location results do not coincide precisely with these concentrically-banded areas, characteristics of discrete intervals of the coastal locations (S1S3) match approximately with the locations of the predicted concentric bands. Furthermore, because of the westward zonal winds, the northern margin of the predicted source area was between the epicenter and the receiver. Therefore, the discrete, localized sources, S1-S3, can be attributed to marginal effects under the atmospheric condition that explains the limited local sources and absence of infrasound signals arriving from mountainous regions located to the left side of the margin. The discrepancies between the location results and the ray density map are interpreted as a function of the complexity of, and differences in, atmospheric structures that could not be explained in the atmospheric model used by this study.

\section{Infrasound Source Scaling}

The observed infrasound signals were corrected according to propagation distance and wind effects to estimate the amplitude at the sources (Whitaker et al., 2003). The corrected amplitude and signal duration (only diffracted infrasound signals detected above PMCC detection thresholds) of the earthquake were compared with those from relatively shallow earthquakes (Le Pichon et al., 2006). The corrected amplitude of the deep earthquake is smaller than the regression trend (dotted line) of shallow earthquakes (Fig. 4(a)), and the amplitude is approximately equivalent to that from a shallow earthquake of magnitude 5. The general trend of signal duration for the deep earthquake shows little difference from the general trend of shallow earthquakes and cannot be used to distinguish deep earthquakes from shallow ones. These comparisons imply that corrected infrasound amplitudes can be used to determine earthquake depth, as had been suggested by Arrowsmith et al. (2011).

\section{Conclusions}

Infrasound signals were recorded from a deep-focus earthquake that occurred at the base of the Pacific plate, where it is being subducted under the Eurasian plate. The infrasound array CHNAR recorded sequential signals consisting of local, near epicentral, and secondary infrasound produced by ground shaking associated with the deep earthquake. Source locations of the epicentral-secondary infrasound signals were searched by matching measurements using a modeled infrasound source map. Source locations of epicentral and secondary infrasound signals were geographically limited to discrete locations, a finding which is explained by a ray density map as the result of largescale atmospheric conditions at the time when the event occurred. Under the prevailing westward zonal winds, only infrasound produced in areas east of the receiver was detectable, even though ground motion may have been produced over a broad area. This study confirmed that atmospheric conditions are critical to the detectability of infrasound signals for distant sources. Even the analyses presented in this study are reasonably well explained by the empirical HWM93 wind model, further studies should incorporate more realistic atmospheric specifications to better characterize the seismic source from remote infrasound observations. Furthermore, given that the excitation mechanism of earthquake-associated infrasound is related to ground motion at the Earth's surface, the characteristics of deep-quake-associated infrasound signals cannot be distinguished from those of shallow earthquakes. Nonetheless, this observation expands the detection regime of infrasound technology, which has hitherto been widely used to study pressure variations caused by natural and anthropogenic phenomena in the atmosphere, into the Earth's deep interior.

This study shows that the corrected amplitude of the deep earthquake is lower than amplitudes of shallow earthquakes. Compared with amplitude data from shallow earthquakes, the corrected amplitude of the deep earthquake was equivalent to that from a shallow earthquake with a magnitude of approximately 5. This implies that ground motion equivalent to that of an earthquake with a magnitude of approximately 5 existed near the epicenter and in surrounding regions that have only sparse seismic network coverage. Four smaller deep earthquakes with magnitudes of 5.7-6.9 have occurred near the hypocenter of this study since the installation of the array, but no associated infrasonic signals were detected by the array. It was reported that relatively shallow earthquakes with a magnitude detection threshold below 5 generate atmospheric infrasound waves through low-frequency oscillation of the Earth's surface (Mutschlecner and Whitaker, 1998; Arrowsmith et al., 2012). Thus, this deep earthquake with a magnitude equiv- 
alent to that of a shallow magnitude 5 earthquake was able to generate detectable infrasound, but ground motions of the other, smaller deep earthquakes were not sufficient to generate detectable infrasound. The observation of a deep earthquake's infrasound amplitude being lower than that of a shallow earthquake of similar magnitude supports the concept that infrasound can be used to determine depth, as suggested by Arrowsmith et al. (2011). Defining this relationship better will require more infrasound measurements of earthquakes at different depths. In addition, since atmospheric conditions significantly affect the propagation of infrasound and determine its detectability and amplitude at the receiver, propagation-path amplitude loss should be considered in the development of an infrasound depthdiscrimination algorithm.

Acknowledgments. We gratefully acknowledge the use of F-net waveform data from the National Research Institute for Earth Science and Disaster Prevention (NIED). This work was supported by the Basic Research Project of the Korea Institute of Geoscience and Mineral Resources funded by the Ministry of Knowledge Economy of Korea.

\section{References}

Antier, K., A. Le Pichon, S. Vergniolle, C. Zielinski, and M. Lardy, Multiyear validation of the NRL-G2S wind fields using infrasound from Yasur, J. Geophys. Res., 112, D23110, doi:10.1029/2007JD008462, 2007.

Arrowsmith, S. J., R. Whitaker, and R. Stead, Infrasound as a depth discriminant, in Proc. 2011 Monitoring Research Review: Ground-Based Nuclear Explosion Monitoring Technologies, National Nuclear Security Administration, Tucson, Ariz, 755-765, 2011.

Arrowsmith, S. J., R. Burlacu, K. Pankow, B. Stump, R. Stead, R. Whitaker, and C. Hayward, A seismoacoustic study of the 2011 January 3 Circleville earthquake, Geophys. J. Int., 189, 1148-1158, doi:
10.1111/j.1365-246X.2012.05420.x, 2012.

Cansi, Y., An automatic seismic event processing for detection and location: the PMCC method, Geophys. Res. Lett., 22, 1021-1024, 1995.

Che, I.-Y., H.-I. Lee, J.-S. Jeon, and T.-S. Kang, An analysis of the infrasound signal from the Miyagi-Oki earthquake in Japan on 16 August 2005, Earth Planets Space, 59, e9-e12, 2007.

Christie, D. R. and P. Campus, The IMS Infrasound Network: Design and Establishment of Infrasound Stations, in Infrasound Monitoring for Atmospheric Studies, edited by A. Le Pichon, E. Blanc, and A. Hauchecorne, 29-75, Springer, 2010.

Frohlich, C., Deep Earthquakes, Cambridge University Press, ISBN 9780-521-82869-7, 2006.

Hedin, A. E., Extension of the MSIS thermosphere model into the middle and lower atmosphere, J. Geophys. Res., 96(A2), 1159-1172, 1991.

Le Pichon, A., J. Guilbert, A. Vega, M. Garcès, and N. Brachet, Ground-coupled air waves and diffracted infrasound from the Arequipa earthquake of June 23, 2001, Geophys. Res. Lett., 29, doi:10.1029/2002GL015052, 2002.

Le Pichon, A., P. Mialle, J. Guilbert, and J. Vergoz, Multistation infrasonic observations of the Chilean earthquake of 2005 June 13, Geophys. J. Int., 167, 838-844, doi:10.1111/j.1365-246X.2006.03190.x, 2006.

Mutschlecner, J. P. and R. W. Whitaker, Infrasonic observations of earthquakes, Tech. Rep. LA-UR-98-2689, Los Alamos Laboratory, 1998.

Mutschlecner, J. P. and R. W. Whitaker, Infrasound from earthquakes, $J$. Geophys., Res., 110, doi:10.1029/2004JD005067, 2005.

Park, S. C. and J. Mori, Rupture velocity estimation of large deepfocus earthquakes surrounding Japan, J. Geophys. Res., 113, B08303, doi:10.1029/2007JB005434, 2008.

Stump, B., M.-S. Jun, C. Hayward, J.-S. Jeon, I.-Y. Che, K. Thomason, S. M. House, and J. McKenna, Small-aperture seismo-acoustic arrays: design, implementation, and utilization, Bull. Seismol. Soc. Am., 94, 220-236, 2004.

Whitaker, R. W., T. D. Sondoval, and J. P. Mutschlecner, Recent infrasound analysis, in Proc. 25th Seismic Res. Rev.-Nuclear Explosion Monitoring: Building the Knowledge Base, 646-654, National Nuclear Security Administration, Tucson, Ariz, 2003.

I.-Y. Che (e-mail: che10@kigam.re.kr), G. Kim, and A. Le Pichon 